\title{
Rasgos etnográficos del arte rupestre naturalista en Murcia
}

\author{
Miguel Ángel Mateo Saura
}

\section{INTRODUCCIÓN}

Si tomamos como punto de partida que el Arte Rupestre Naturalista es el fiel reflejo de un modo de vida que nos permite adentrarnos en las ideas de sus autores sobre la belleza y las formas, en sus ritos y ceremonias, en creencias sociales y religiosas (BELTRÁN, A. 1989: 57), no cabe duda de que la aplicación de una lectura etnográfica en el estudio de ese arte nos permitirá conocer mejor a aquellos grupos humanos que lo desarrollaron.

La importancia de esta línea de investigación basada en el análisis etnográfico de las representaciones fue ya captada desde los comienzos del estudio de las mismas, sobresaliendo el trabajo de P. Wernert (1917), si bien no tuvo la continuidad que cabría esperar. Ha sido a partir de la década de los setenta cuando este tipo de estudios vuelven a cobrar interés, destacando los trabajos de F. Jordá (1971a; 1971b; 1974; 1975a; $1975 \mathrm{~b}$ ), en los cuales analiza detenidamente diversos aspectos presentes en las pinturas. A él se debe una ordenación tipológica de los tocados de plumas; describe lo que interpreta como instrumentos propios de la actividad agrícola, como son los bastones de cavar, las layas e incluso, un arado; realiza una primera ordenación tipológica de las puntas de flecha, para las que busca paralelos materiales cercanos y realiza también el análisis de la sociedad tal y como ésta se nos presenta a través de las representaciones, concluyendo que se trata de una sociedad matrilineal. Algunas de las conclusiones a las que llega en estos estudios parciales son recogidas en un único trabajo que bajo el título de "Formas de vida económica en el Arte Rupestre Levantino" viene a ser una síntesis de su pensamiento acerca de estas manifestaciones artísticas y de sus autores.

Hemos de resaltar también los estudios de $M .^{a} \mathrm{C}$. Blasco Bosqued $(1974 ; 1975 ; 1981)$, en los que con un carácter eminentemente descriptivo, 
intenta desentrañar la información contenida en ese arte, aunque sin buscar posibles paralelos materiales. Actividades como la caza o la recolección son analizados a partir de las composiciones representadas, planteando probables estrategias y técnicas, así como los útiles e instrumentos empleados en cada una de esas actividades por el hombre, el cual es a su vez estudiado en sus diversas formas de representación.

Junto a estos, otros estudios más concisos tratan de completar esta visión del Arte Naturalista. Las composiciones de lucha entre grupos humanos son recopiladas por M. ${ }^{a}$ I. Molinos Sauras (1986-87), lo que ha permitido conocer algunas estrategias de combate utilizadas, el armamento y una cierta jerarquización social, al menos, en lo que a la guerra se refiere.

Los últimos trabajos globales en los que se ha aplicado la lectura etnográfica a las pinturas de carácter naturalista han sido los realizados por M. ${ }^{a}$ Francia Galiana $(1985 a ; 1985 b)$, si bien éstos se han reducido a un ámbito físico concreto como es el de la Comunidad Valenciana. A pesar de que se trata de límites administrativos actuales, completamente artificiales, han servido para poner de manifiesto la existencia de importantes diferencias "regionales" dentro del Arte Naturalista, aun aceptando la unidad última del fenómeno artístico rupestre en cuanto a origen y motivación. Así, recogiendo el testigo de $F$. Jordá en lo que a las puntas de flecha se refiere, ordena nuevamente los tipos de punta pintados y matiza alguna de las asociaciones establecidas entre el arte y la cultura material, realizando también un análisis más general de los rasgos etnográficos presentes en los conjuntos de la zona de estudio.

Por lo que respecta a Murcia, hasta el momento carecíamos de un estudio de este tipo, encontrando tan sólo breves referencias incluidas en los trabajos particulares efectuados sobre los distintos conjuntos. Ello nos ha llevado a la realización de este trabajo con el fin de cubrir un vacio existente en la investigación sobre el arte rupestre de la provincia, conscientes de que tan sólo un detallado análisis de todos y cada uno de los rasgos que concurren en ese arte, entre los que se encuentran éstos de los que nos ocupamos, reportará datos valiosos acerca del mismo y de aquellos quienes lo crearon.

\section{ANÁLISIS ETNOGRÁFICO}

Para el estudio de los rasgos etnográficos contenidos en los diversos frisos naturalistas murcianos (fig. 1), hemos formado cuatro grupos principales: objetos-útiles, adorno, vestido y peinado. En cada uno de ellos 


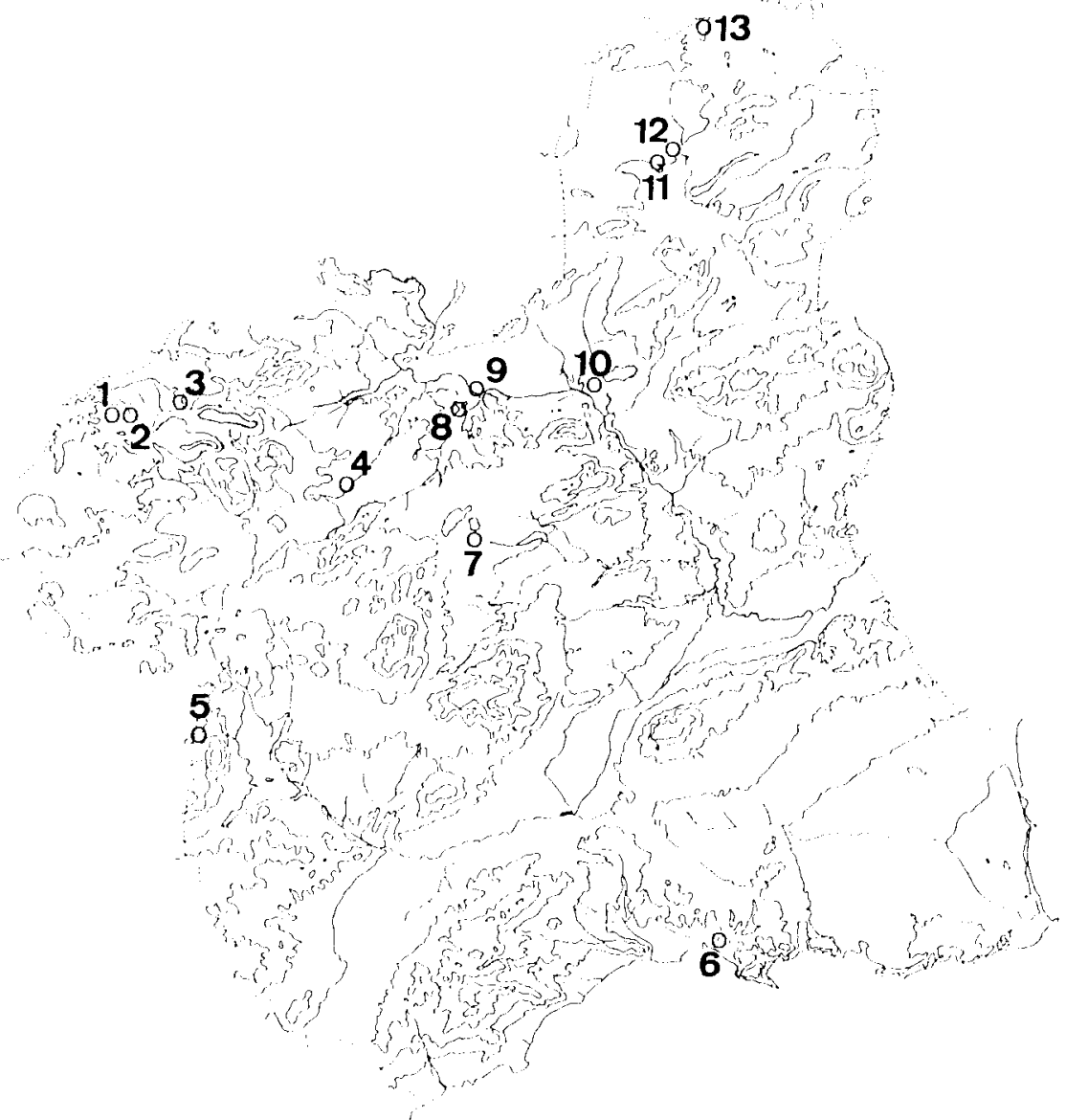

Fig. 1. Localización de conjuntos con arte naturalista en Murcia: 1. Fuente del Sabuco (Moratalla); 2. Cañaica del Calar (Moratalla); 3. La Risca (Moratalla); 4. Peña Rubia (Cehegín); 5. Abrigo del Mojao (Lorca); 6. Cueva de la Higuera (Cartagena); 7. Abrigo del Milano (Mula); 8. Cueva de los Pucheros (Cieza); 9. Cueva de la Serreta I (Cieza); 10. Abrigos de los Grajos (Cieza); 11. Cueva del Peliciego (Jumilla); 12. Abrigos del Buen Aire (Jumilla); 13. Cantos de la Visera (Yec/a).

hemos establecido una tipología en la que hallamos tipos, designados con números romanos, subtipos, designados con números arábigos, y en ocasiones, variantes, designadas con letras minúsculas.

El esquema básico que hemos desarrollado podemos resumirlo de la forma siguiente: 
A: Objetos-útiles

A.1: Armas/Objetos de producción

A.1.1: Arcos

A.1.2: Flechas

A.1.3: Lanza-jabalina

A.1.4: Hachas

A.1.5: Objetos varios

A.2: Recipientes

A.2.1: Carcajes

B: Adorno

B.1: Adorno de cabeza

8.1.1: Diadema

B.1.2: Tocados de Plumas

B.1.3: Varillas

B.1.4: Pendientes

B.1.5: Máscaras

B.2: Adorno de brazos

B.2.1: Cintas o lazos

C: Vestido

C.1: Pantalón largo

C.2: Pantalón ancho y corto

C.3: Vestido largo

C.4: Faldas

C.4.1: Faldas acampanadas

C.4.2: Faldas triangulares

C.4.3: Falda globular

D: Peinados-cabelleras

D.1: Melena

D.2: Cabellera bilobulada

D.3: Cabellera trilobulada 

D.4: Peinado triangular
D.5: Peinado elíptico
D.6: Peinado en trapecio invertido
D.7: Moño
D.8: Cabellera circular
D.9: Peinado ovoide
D.10: Peinado alto

\section{A. OBJETOS/ÚTILES}

\section{A.1. Armas/Objetos de producción}

\section{A.1.1. Arcos}

El arco, instrumento formado por una vara delgada y muy flexible, por lo general de madera, y una cuerda o hilo, quizás tripa animal, puede ser considerado bien como arma, bien como objeto de producción. El contexto en el que se inscriba será el que determine su carácter en uno u otro sentido.

Del análisis de los diversos conjuntos hemos establecido dos tipos básicos en cuanto a la forma. De un lado, el arco simple, con varios subtipos, y de otro, el arco compuesto. En este segundo tipo habría que incluir los que $F$. Jordá (1974: 211) denomina como "arco reflejo" y $E$. Ripoll (1968: 174) como "arco semi-reflejo". Sin embargo, pensamos que no se trata de auténticos arcos compuestos y coincidimos con E. Ripoll (1968: 173) en reservar esta definición para aquellos cuya vara está formada por varias piezas, lo cual no podemos corroborar en las representaciones analizadas.

En lo que se refiere a la actitud de los arqueros, considerando como tales a aquellos personajes provistos de este objeto, esté o no en actitud de disparo, ésta es muy variada. Los hay en posición totalmente estática (Abrigo del Milano), y corriendo (Abrigo del Mojao o Cañaíca del Calar). Cuando la actividad desarrollada es la caza, el arco es sostenido indistintamente con la mano izquierda (Abrigo del Mojao y Peña rubia) o con la derecha (Cañaica del Calar), al tiempo que con la mano contraria se sujetan las flechas o la cuerda del arco. Excepcionalmente, hay un individuo que en acción clara de disparo sujeta el arco cargado únicamente con la mano izquierda (Cueva-sima de la Serreta I).

Si se trata de combate o lucha, de la única composición de este tipo que hemos estudiado (Fuente del Sabuco), deducimos dos posturas fun- 
damentales. De un lado, los personajes involucrados directamente en esa lucha, en actitud de carrera, sujetan el arco con la mano derecha a la altura del pecho, mientras que aquellos individuos que permanecen al margen del combate y en otro plano de representación, sostienen el arco con ambas manos a la altura de la cintura.

Por su parte, en la composición de desfile militar analizada (Fuente del Sabuco), los arqueros sujetan el arma, junto con las flechas, con la mano izquierda.

Atendiendo a la curvatura de la vara hemos establecido dos subtipos dentro del tipo general de arco simple:

- Tipo I: Arco simple

- Subtipo l: Arco simple convexo

La vara del arco se curva formando junto con la cuerda atada en sus extremos un semicírculo. Este tipo de arco es el más abundantemente representado en los conjuntos naturalistas (BLAsco M. C. 1974: 29-55), manteniéndose esa correspondencia en los conjuntos murcianos. Lo observamos en las estaciones de la Peña Rubia (Cehegín), Abrigo del Milano (Mula), Abrigo del Mojao (Lorca), Cañaíca del Calar (Moratalla) y en la Fuente del Sabuco (Moratalla) (fig. 2, núm(s). 1-9).

La plasmación de pequeños detalles nos ha permitido determinar dos variantes dentro del tipo general. La variante a muestra unas escotaduras en los extremos de la vara del arco en las que se ha insertado la cuerda. Esta escotadura se señala haciendo coincidir la cuerda o bordón con la vara antes de llegar al extremo de ésta. Se localiza la variante a en los conjuntos del Abrigo del Mojao (Lorca), el Abrigo del Milano (Mula) y la Cañaíca del Calar (Moratalla) (fig. 2, núm(s). 6-8) estando asociados a composiciones de caza. La variante b presenta en lugar de las escotaduras unos extremos de la vara bastante engrosados, estando provocado ese engrosamiento por la inserción de la propia cuerda. Lo observamos en el conjunto de la Peña Rubia de Cehegín (fig. 2, núm. 9).

\section{- Subtipo 2: Arco simple biconvexo}

La vara del arco describe dos curvas convexas, delimitando junto con la cuerda, dos espacios semicirculares. Se localizan en la Cueva-sima de la Serreta I (Cieza) y en la Fuente del Sabuco (Moratalla) (fig. 2, núm(s). 10-11) y se asocian a composiciones de caza de grandes cuadrúpedos el primero y a un contexto de enfrentamiento bélico el segundo.

- Tipo 11: Arco compuesto. 
No hemos identificado ningún ejemplo de arco compuesto en los diversos abrigos estudiados, entendiendo como tales arcos compuestos a aquellos cuya vara está formada por dos o más piezas unidas entre sí.

\section{A.1.2. Flechas.}

La flecha, representada en íntima asociación con los arcos, consta de tres partes fundamentales como son el astil, y en cada uno de los extremos de éste, una punta y una emplumadura, respectivamente.

El astil debió ser de madera, ya que por su poco peso favorece al vuelo de la flecha. Su sección era variada si nos atenemos a los restos de astil recuperados. En la Cueva del Peliciego de Jumilla se exhumaron hasta 74 vástagos de flecha, fabricados en madera de pino y con secciones tanto circulares como rectangulares (MOLINA, M. et alii 1973: 160).

Refiriéndose a la punta, en ocasiones puede estar formada por la propia madera del astil, la cual ha sido aguzada y endurecida al fuego.

Por su parte, la emplumadura de dirección puede no estar presente, lo que parece testimoniar que la flecha era empleada para lanzarla a cortas distancias, al contrario que sucede con una flecha dotada de emplumadura, formada muy posiblemente por simples plumas de ave sujetas al extremo basal del vástago por medio de resinas (GALIANA, M. F. 1985b: 25), que permite ser lanzada a larga distancia, confiriéndole mayor estabilidad y precisión al disparo.

Tan sólo en dos conjuntos murcianos hay representación de estas emplumaduras, Abrigo del Mojao (Lorca) y Abrigo del Milano (Mula), pero basta para poner de manifiesto cierta diversidad en la misma, si no en lo referente al material empleado, que como decimos pudieron ser plumas de ave, si en cuanto al número de éstas empleadas en cada caso.

Así, podemos establecer diversas variantes en función de este hecho. La variante a muestra una emplumadura de una sola pluma (fig. 2 , núm. 12); la variante «b» presenta tres plumas (fig. 2 , núm(s). 7 y 12 y la variante "C» engloba a aquellas emplumaduras compuestas por cuatro plumas (fig. 2, núm. 12). Por otro lado, ejemplos de flecha sin emplumadura los hallamos en el Abrigo del Milano (Mula) y en la Fuente del Sabuco (Moratalla) (fig. 2, núm(s). 6 y 13).

Para el estudio de las "puntas de flecha" mantenemos en la medida en que nos ha sido posible aquellos tipos ya establecidos en trabajos anteriores (BLASCO, M. C. 1974; JoRdA, F. 1975; GaLIANA, M. F. 1985b).

- Tipo I: Punta de astil aguzado o simple. 


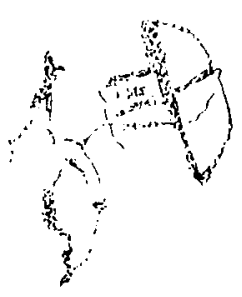

1

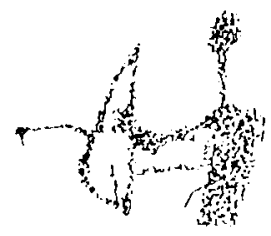

5

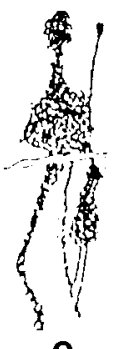

9

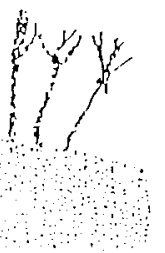

12

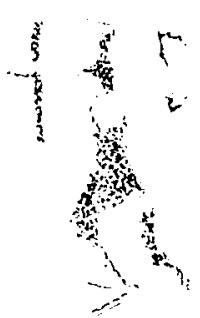

2

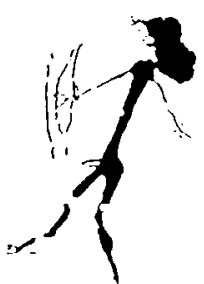

6

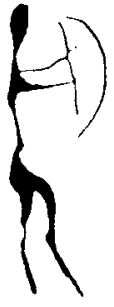

3

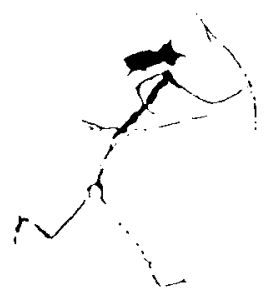

7

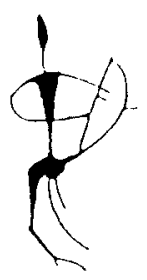

4

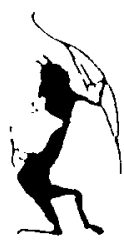

8

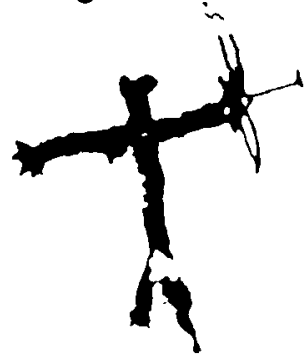

10

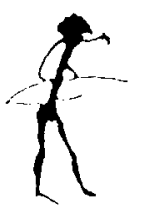

11

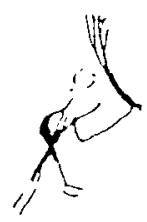

13

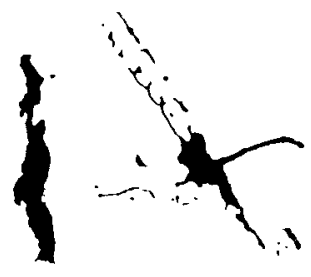

14

Fig. 2. ARCOS-FLECHAS: 1-5, Peña Rubia (BELTRÁN-SAN NICOLÁS 1988), 6, El Milano (SAN NICOLÁs et alii 1988);7, El Mojao; 8. Cañaica del Calar (BELTRÁN, 1972); 9. Peña Rubia (Beltrán-San Nicolás, 1988); 10. La Serreta (Mateo Saura, 1992); 11. Fuente del Sabuco (BELtrán, 1972); 12. Peña Rubia (Beltrán-San Nicolás, 1988); 13. Fuente del Sabuco (BELTRÁn, 1972); 14. La Serreta (MATEO Saura, 1992). 
El propio astil o vástago de la flecha ha sido aguzado y muy posiblemente endurecido al fuego, para constituirse de esta forma en la punta de esa flecha (fig. 2, núm(s). 6, 7 y 14). Este tipo es el más representado en los conjuntos de Arte Naturalista y en Murcia lo hallamos en el Abrigo del Milano (Mula) y en el Abrigo del Mojao (Lorca).

Un caso curioso y excepcional, que no consideramos como subtipo, se localiza en el conjunto ciezano de la Cueva-sima de la Serreta I en donde un arquero en actitud de disparo porta una flecha cuya punta, rectilínea, se curva hacia abajo rompiendo el eje con el vástago (fig. 2, núm. 14). La aceptamos como una flecha con punta de ápice simple o astil aguzado porque creemos que la causa de tal inflexión es un pequeño saliente en la roca, que el "artista» prefiere eludir curvando el trazo de la flecha antes que pintar sobre él, lo que rompería la continuidad del mismo.

El tipo de punta de flecha de astil aguzado es portada por arqueros inmersos en composiciones de caza.

- Tipo II: Punta de forma foliácea o tendencia romboidal.

En este tipo se marca una distinción entre el astil de la flecha y la punta, lo que parece indicar el empleo de un material diferente en la fabricación de esa punta al utilizado para el astil. Si este era preferentemente de madera, la punta puede ser más variada, entrando a participar otros materiales como puedan ser el sílex, el metal o el hueso. Este tipo de punta de tendencia romboidal se localiza únicamente en el conjunto de la Peña Rubia de Cehegín (fig. 2, núm(s). 1 y 5 ).

- Tipo III: Punta de forma triangular.

La forma triangular que presenta este tipo de punta nos recuerda mucho a las puntas con pedúnculo y aletas, elaboradas sobre todo en sílex, de amplio encuadre cronológico. En el Arte Naturalista de los conjuntos murcianos tan sólo la documentamos en el abrigo $1 .^{\circ}$ de la Fuente del Sabuco, de Moratalla (fig. 2 núm. 13).

- Tipo IV: Punta en T transversa.

Este particular tipo de punta de flecha que hemos dado en llamar de $T$ transversa está formada por un trazo de considerables proporciones perpendicular al vástago de esa flecha.

En principio creeemos que no guarda ninguna relación con el subtipo 4 de $M .^{a}$ F. Galiana (1985b: 31) que la autora define como "punta de ganchos", o con el tipo D de F. Jordá (1975a: 221), definido como "punta de diente de arpón". En ambos casos se trata de puntas en las que desde el propio ápice del astil arranca un trazo recto y ligeramente oblicuo, otorgando ese aspecto de gancho o arpón. En la punta pintada en la 
Cueva-sima de la Serreta I (Cieza), no hay un sólo trazo al final del ápice, sino dos, algo engrosados y con una disposición perpendicular al astil, lo que nos lleva a proponerlo como un tipo más de punta por sí misma (fig. 2, núm. 10).

En resumen, acerca de los tipos de puntas de flecha constatados, podemos decir que el tipo más extendido es el de "astil aguzado", presente en tres conjuntos, mientras que los otros tipos definidos solo los hallamos en un conjunto cada uno de ellos.

\subsubsection{Lanza-jabalina.}

Dentro del armamento empleado por el autor del Arte Naturalista y en función del número de representaciones existentes, hemos de considerar que las armas arrojadizas del tipo de las lanzas o jabalinas desempeñaron un papel secundario.

La causa para un menor porcentaje en las representaciones tal vez se deba a una utilización también menor en la realidad por parte de los cazadores, ya que supone un aumento del nivel de riesgo para dicho cazador sobre todo si lo comparamos con el arco y las flechas. Mientras con estos se pueden lograr grandes distancias, en torno a los $100 \mathrm{~m}$ (Rozor, J. C. 1978: 1012), con una jabalina la distancia se reduce en torno a la mitad, con lo que el peligro que pueda suponer el animal para ese cazador es más acusado que con el arco. De otra parte, el poder matar a un animal a una distancia de $100 \mathrm{~m}$, facilita indudablemente las estrategias de caza, ya que el cazador puede pasar inadvertido durante más tiempo y acercarse asi a su presa.

Sin embargo, hay abierta una polémica entre los investigadores a la hora de aceptar como tales armas arrojadizas los, de otro lado, escasos ejemplos pintados. El individuo de la Cueva del Garroso de Alacón (Teruel) que parece ir provisto de dos de estas jabalinas, es descrito como tal por algunos autores (Ortego, T. 1948; Almagro, M. 1956; Beltrán, A. 1968), mientras que otros lo han interpretado como un instrumento agrícola, como una laya (JoRDA, F. 1971a: 246). Otros ejemplos como los de la Galería Alta del Roure o el Val del Charco del Agua Amarga se prestan también a cierta confusión (BLASCO, M. C. 1974: 49).

No obstante, creemos que algunas otras figuraciones nos permiten confirmar la existencia en los frisos pintados y su utilización por parte de los cazadores autores del arte de estas armas arrojadizas. Individuos de la Cueva del Civil de la Valltorta (Castellón) y otro personaje de la Cueva de la Saltadora (Castellón) (VIÑAS, R. 1982) van equipados con estas armas. Al no ir armados con arcos nos obliga a rechazar la idea de que se trate de venablos de largo astil, proponiéndolas como tales jabalinas. 
En el conjunto murciano de la Peña Rubia de Cehegín, más en concreto en la Cueva de las Conchas, un individuo porta con absoluta claridad un largo bastón en el que se aprecia con nitidez una diferenciación entre el astil y la punta (fig. 3 , núm. 1). Más problemático resulta aceptar como jabalina el arma que lleva otro individuo en el conjunto de la Fuente del Sabuco de Moratalla, interpretado por A. Beltrán (1972: 84) como un simple arquero (fig. 3 , núm. 2). Si bien pudiera tratarse de un arquero al modo propuesto, afectado por la acusada tendencia a la esquematización a la que están sometidas todas las figuras antropomorfas del conjunto, hemos de señalar, no obstante, que en otros individuos armados con un instrumento rectilíneo se ha remarcado algún trazo curvo, aunque sea mínimamente, para indicar que se trata de un arco y el posible venablo, lo cual no sucede con éste a que hacemos referencia.

Por otro lado, la representación en este conjunto de otras armas poco frecuentes en los frisos naturalistas como puedan ser las hachas, puede apoyar esta interpretación que hacemos como jabalina, también con carácter de excepción en el panel pintado.

Planteada la posibilidad de este último ejemplo, podemos establecer dos tipos de arma arrojadiza:

- Tipo I: Astil aguzado.

En este tipo no se manifiesta una clara diferenciación entre el astil del arma y la punta, sino que como sucede en algunos tipos de flechas, la propia madera del astil ha sido previamente trabajada para darle una forma apuntada. El único ejemplo con que contamos se cuentra en el abrigo 1. ${ }^{\circ}$ de la Fuente del Sabuco (Moratalla) (fig. 3, núm. 2), en un contexto de enfrentamiento bélico que preside todo el friso pintado.

- Tipo II: Jabalina de punta lanceolada.

Se marca una separación entre el astil del arma y su punta, que en este caso muestra una forma claramente lanceolada. Se localiza en la Cueva de las Conchas, dentro del conjunto de la Peña Rubia de Cehegín, y el individuo que la lleva está inmerso directamente en tareas de caza junto a otros personajes armados con arcos y flechas (fig. 3 , núm. 1).

\subsubsection{Hachas.}

Si escasas en ejemplos y problemáticas en su interpretación eran las lanzas-jabalinas, no deja de ser muy distinto el panorama que rodea a las hachas. Con algunas reservas al respecto se han apuntado como tales ciertos objetos pintados en la Cueva del Rug de Tirig (Castellón), la Cueva del Polvorín (Castellón) y en la Cueva de la Vieja de Alpera (Albacete) 


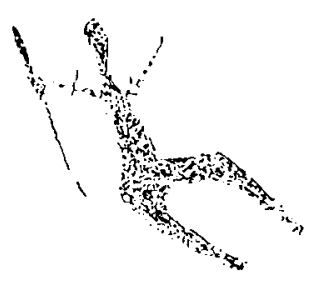

1

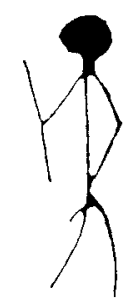

2

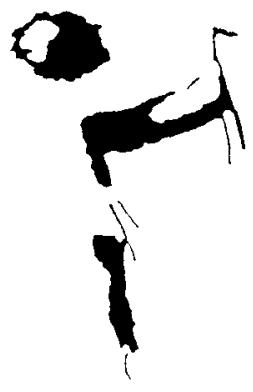

3

Fig. 3. JABALINAS-HACHAS: 1. Peña Rubia (BELTRAN-SAN NICOLÁS 1988); 2-3. Fuente del SabUCO (BELTRÁN, 1972).

(Galiana, M. F. 1985a: 83) sin que en ninguno de ellos se pueda afirmar con certeza que estemos ante la representación de un hacha.

Sin embargo, en el abrigo 1. ${ }^{\circ}$ de la Fuente del Sabuco de Moratalla contamos con un ejemplar indiscutible de hacha enmangada (fig. 3, núm. 3). Curiosamente, ni el individuo que lleva el objeto ni el propio arma en si fueron analizados en los apartados correspondientes a la descripción de motivos y síntesis de la monografía publicada a raíz del descubrimiento de estas pinturas (Beltrán, A. 1972). Se trata de un individuo que parcialmente conservado lleva un hacha enmangada en su mano izquierda, apreciándose como en el astil hay dos trazos que interpretamos, uno como el astil propiamente dicho y el otro como algún elemento de adorno, un lazo quizá, sujeto a ese mango.

Por la temática dominante en el conjunto, con una composición de lucha entre dos bandos diferenciados, otorgamos a este objeto el carácter de arma y no de objeto de producción, si bien la alternancia en estas 
funciones las determinarían las necesidades del momento y la propia actividad desarrollada.

\subsubsection{Objetos varios.}

Incluimos en este apartado una serie de objetos a los que damos una interpretación concreta más en función del contexto en el que se inscriben que por su forma. Podemos establecer así varios grupos:

- Grupo I: lo forman aquellos objetos que por su inclusión en ambientes de caza y lucha consideramos como armas u objetos de producción. Atendiendo a las características particulares de cada uno de ellos se pueden determinar varios subgrupos.

- Subgrupo 1. Está constituido por una representación alargada y relativamente gruesa, sujeta por un individuo con ambas manos (fig. 4, núm. 1). Se encuentra en la Cueva del Humo, en el conjunto de la Peña Rubia de Cehegín. Por sus características diferentes a las del resto de objetos representados en el conjunto, no parece tratarse ni de un arco ni de una jabalina, si bien por el contexto de actividad cinegética en que aparece debemos consideralo como un instrumento más de los empleados en las tareas de caza.

- Subgrupo 2. Pintada también en el conjunto de la Peña Rubia de Cehegín, aunque en la Cueva de las Palomas, es una representación formada por un trazo vertical, coronado por otro trazo perpendicular al anterior y de forma ligeramente curva (fig. 4, núm. 2). Por su inclusión en una composición de caza lo interpretamos como un tipo particular de arma cuya morfología podría tener paralelismos más o menos cercanos en las hachas enmangadas.

- Subgrupo 3. Lo integra la representación de un objeto biconvexo portado por una figura femenina del abrigo $1 .^{\circ}$ de la Fuente del Sabuco de Moratalla (fig. 4, núm. 4). Se incluye en un contexto de enfrentamiento bélico y aunque hay suficientes diferencias formales con las hachas enmangadas, también presentes en el conjunto, debemos concluir que su finalidad no debió ser muy distinta a la de aquellas.

- Subgrupo 4. Es una representación filiforme, casi paralela al cuerpo del individuo que la lleva y unida a este por una línea perpendicular (fig. 4, núm. 3). Sin que podamos precisar más sobre su interpretación no somos partidarios de considerarla como la representación de un arco, tal y como se ha propuesto (BeLtRán, A. 1972: 63), sobre todo teniendo en cuenta la linealidad que muestra, su forma 


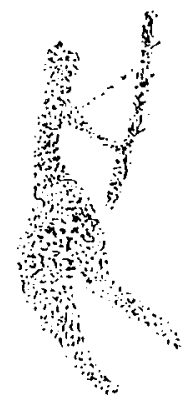

1

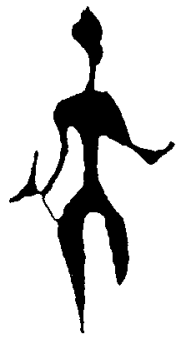

2

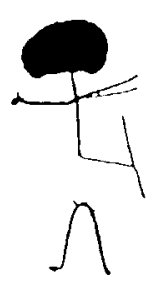

3

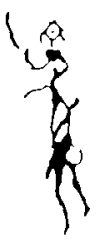

4

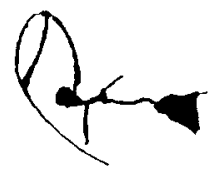

5

Fig. 4. OBjetos VARIOS: 1-2. Peña Rubia (BELtRÁ-SAn Nicolás, 1988); 3-5. Fuente del SabUCo (BELTRÁN. 1972).

de engarce y su alejamiento formal respecto al resto de representaciones de arco que observamos en el conjunto.

- Subgrupo 5. Lo integra un trazo curvilineo, de forma casi ovoide, atravesado en su tercio superior por una línea ligeramente arqueada y unido a su vez a un trazo recto horizontal (fig. 4, núm. 5). Se localiza en el conjunto de la Fuente del Sabuco (Moratalla) y su situación aislada dentro del friso impide realizar valoración alguna sobre su significado o función.

\section{A.2. Recipientes.}

\section{A.2.1. Carcajes.}

Dentro del grupo de los recipientes sólo hemos identificado dos carcajes, sin que hayamos podido leer ningún otro tipo de objeto que cumpla la misma función de transporte en los conjuntos estudiados.

En los abrigos del Barranco de los Grajos (Cieza), A. Beltrán (1969: 62) interpretó una figura femenina en la que «debajo de su mano izquierda hay una mancha circular roja" considerada con cierta cautela como un 
recipiente esférico. El que careciera de señales de borde o cualquier otro elemento de sujeción llevó más tarde a plantear dudas sobre esta interpretación (GALIANA, M. F. 1985a: 78). Por nuestra parte, tras la relectura que hemos efectuado de estas pinturas podemos afirmar que la antedicha mancha circular descrita por A. Beltrán no es sino la mano de la figura femenina en la que además se aprecian hasta tres dedos de forma clara. Ello elimina toda posibilidad de que se trate de algún objeto, en concreto, del tipo de una bolsa, similar a las que encontramos en otros conjuntos como la Cueva Remigia (Castellón) (PorCAR, J. B. et alii 1935), cuya característica esencial es la ausencia de asa (GALIANA, M. F. 1985a: 78) y menos aún del tipo de un cesto, que se observa en conjuntos como la propia Cueva Remigia (Castellón) o el Racó de Molero (La Gasulla, Castellón) (RIPOLL, E. 1963), entre otros ejemplos.

Como decíamos, tan sólo hemos definido dos carcajes, siendo distintos en su tipología. El carcaj es un recipiente alargado, destinado a albergar las flechas y facilitar asi su transporte por parte del arquero, ya sea para la caza o para la guerra. El material en que debieron fabricarse debió ser resistente y ligero, propiedades que reúne el cuero o el mimbre (ESTEVE, F. 1974: 11), aunque también se ha apuntado la posibilidad de que se usase la madera (GalianA, M. F. 1985a: 78). Creemos, empero, que el empleo de esta última, por sus características de rigidez estaba en desventaja desde el punto de vista funcional respecto a aquellos otros, sobre todo respecto al cuero. Considerando una serie de trazos entrecruzados en el interior de un recipiente representado en la Cueva Remigia (Castellón) se ha postulado también un probable trabajo de cestería en la confección de este tipo de objetos destinados al transporte (BLASCO, M. C. 1974: 51).

Dentro del tipo general de carcaj que podemos definir como objeto de especto cilíndrico, estrecho y alargado, se pueden determinar los siguientes subtipos:

\section{- Subtipo 1: Carcaj de forma rectangular}

En él, tanto la boca como la base están representadas con trazos rectos y perpendiculares a los laterales, dándole ese aspecto de rectángulo. Se localiza en el abrigo $11 .^{\circ}$ de la Fuente del Sabuco (Moratalla) (fig. 5 , núm. 1), y sus paralelos más directos podrían ser los de la Cueva de la Saltadora (Castellón) (VIÑAS, R. 1982: 120).

- Subtipo 2: Carcaj de forma cónica

En este subtipo, el extremo de la base ha sido apuntado y determinado por un trazo curvo, lo que le confiere ese aspecto cónico. Lo hallamos en la Cueva de las Palomas, dentro del conjunto de la Peña rubia (Ce- 


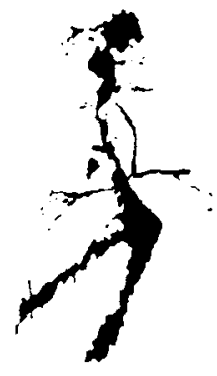

1

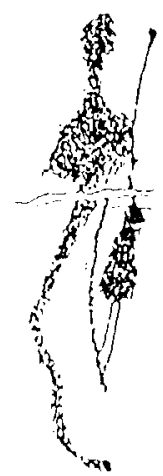

2

Fig. 5. RECIPIENTES: 1. Fuente Sabuco (Alonso-Grimal, 1985); 2. Peña Rubia (BELTRÁN-SAN NICOLÁS, 1988).

hegín) y lo porta un individuo armado con arco, estando unido directamente al extremo inferior de ese arco y sobresaliendo de él el vástago de dos flechas (fig. 5 núm. 2).

La posición invertida de este carcaj y la presencia de dos flechas en su interior nos lleva a pensar en la existencia de algún tipo de cierre para este recipiente, lo cual resulta lógico si consideramos que en muchas ocasiones los arqueros van lanzados a la carrera con este carcaj repleto de flechas que de no ir sujetas caerían al suelo. No faltan ejemplos de individuos en plena acción de carrera y provistos de un carcaj con venablos. Un caso claro lo tenemos en varios arqueros de la cueva Remigia (Castellón) (PorCar, J.B. et alii, 1935) o en la Cueva del Civil (Castellón) (VIÑAS, R. 1982). Al mismo tiempo, este rasgo apoya la idea de la meleabilidad del material empleado, lo cual habla más en favor de materiales del tipo del cuero que de la madera.

\section{B. ADORNO}

Establecemos una clasificación del adorno en función del lugar corporal en el que se localiza, diferenciando a partir de este agrupamiento varios subtipos.

Hemos de reseñar previamente que los elementos de adorno presentes en las estaciones naturalistas de Murcia son más bien escasos, observándose una acusada concentración en el conjunto de la Fuente del Sabuco de Moratalla, más concretamente en su abrigo $\mathrm{I}^{\circ}$, en el que se aprecia una notable variedad al respecto no exenta de cierta originalidad. 


\section{B.1. Adorno de cabeza}

Diferenciamos hasta cinco tipos básicos en virtud a la clase de elemento que se emplea como tal adorno.

- Tipo I: Diadema (fig. 6, núm(s). 1-4)

Este objeto es quizás el que se encuentre presente en la mayor parte de las figuras antropomorfas y curiosamente, en la mayoria de las ocasiones no es posible visualizarlo de manera directa.

Como expone M. ${ }^{a}$ F. ${ }^{a}$ Galiana (1985a: 57 ), "entendemos por tales diademas las cintas que ciñen el pelo a la altura de las sienes con la doble función de retener y adornar el peinado». Al respecto hemos de reseñar la manifiesta dificultad de discernir si en el empleo de estas diademas primaba más un sentido de funcionalidad que un deseo real de ornato. Sea un caso u otro, la realidad es que su empleo se refleja en un alto porcentaje de figuras, de ambos sexos, dentro del Arte Naturalista, dando lugar a una amplia gama de peinados, por lo que su consideración como objeto de adorno y su inclusión en este grupo puede quedar justificada.

Pero, si como hemos apuntado, en las figuraciones no se aprecia su existencia de forma directa, ¿cómo podemos constatar si existe o no? La forma de la cabeza de cada figura responde a esta interrogante. La formación de masas de cabello, por lo general dos o tres, a los lados de la cabeza se debe a la presión ejercida por la supuesta diadema sobre ese cabello.

El material con que se debieron elaborar tuvo que ser del tipo del cuero o algún material vegetal, que por su flexibilidad y ligereza son idóneos para ello, aunque también F. Jordá (1974: 221) ha apuntado la posibilidad de que se emplee metal para confeccionar estas diademas, estando entonces formadas por un elemento interior adaptado a la cabeza y hecho con corteza, madera, tela gruesa o incluso metal y otro elemento exterior, de forma laminar y elaborado con metal, principalmente oro 0 plata.

Aunque la forma de los peinados constituye ya de por si un argumento sólido acerca del empleo de estas diademas, indispensables para originar esas formas tan variadas con el cabello, contamos en el conjunto de La Risca de Moratalla con una excepcional representación en la que se observa nítidamente la propia diadema que también ha sido pintada (fig. 6 , núm. 1). La figura femenina más pequeña presenta una cabeza de forma triangular en la que se distinguen dos masas laterales redondeadas. En la parte de la izquierda de la cabeza, por encima y por debajo de la masa de cabello sobresalen dos reducidos trazos que no dudamos en interpretar 
como los extremos de una cinta o lazo que actuaría como elemento de sujeción $y$, por tanto, como una de estas diademas.

Este testimonio gráfico es lo suficientemente importante sobre el particular, sirviendo, asimismo, para apoyar la idea de que para la elaboración de estos objetos se utilizaba un material flexible, no metal, que al ser atado podía dar lugar a un lazo cuyos extremos podían a su vez permanecer separados en sentido opuesto, como sucede en este ejemplo moratallense. Una diadema de metal mantendría sus extremos a una misma altura sin que sobresaliesen, ya que por su rigidez se adaptaría perfectamente a la cabeza.

En ocasiones, las diademas se asocian a otros elementos de adorno, como puedan ser las plumas, para las que servía como soporte. Se podrían establecer así dos variantes, una variante a formada por la diadema exclusivamente y una variante $b$, en la que junto a la diadema hallamos también otros elementos.

Estas diademas las llevan tanto las figuras masculinas como las femeninas, siendo indiferente la actividad que desempeñen. Así, se constata en composiciones de caza, de lucha y de danza.

- Tipo II: Tocados de plumas (fig. 6, núm(s). 5-7)

Ante todo creemos que conviene aclarar que entendemos por tocado y cuando hablamos de tocado. Consideramos como tal la combinación intencionada del cabello con algún otro elemento externo, de naturaleza variada, con una finalidad no exclusiva de ornato. Si no existe esa combinación, preferimos hablar de peinado o cabellera, pero no de tocado.

En este caso en particular sería el tratamiento conjunto del cabello con plumas procedentes de animales. Si bien existe una apreciable variedad en cuanto a la forma y tamaño de las plumas, podemos definir como tales a «uno o varios apéndices, largos o cortos, cuya base de contacto con la cabeza suele ser estrecha» (GalianA, M. F. 1985a: 58).

En virtud al número de apéndices que conforman el tocado, podemos diferenciar varios subtipos:

\section{- Subtipo 1: Tocado de 1 pluma}

Se trata de un tipo de tocado formado por una sola pluma cuyas dimensiones y forma puede variar ostensiblemente de unos ejemplos a otros, dando lugar a diferentes variantes. Una variante a sería la determinada por el penacho que porta uno de los arqueros del abrigo $1 .{ }^{\circ}$ de la Fuente del Sabuco (Moratalla), el cual presenta un tamaño considerable, con los extremos estrechos y el centro muy engrosado (fig. 6, núm. 5). 
Una variante b la definirian aquellas plumas de forma lanceolada con extremos apuntados (fig. 6, núm. 6).

- Subtipo II. : Tocado de 2 plumas

En Murcia tan sólo lo documentamos en el conjunto de la Cañaíca del Calar (Moratalla) en donde un arquero en actitud de disparo lleva en la cabeza un tocado de este tipo (fig. 6: núm. 7). En la descripción de esta figura A. Beltrán (1972: 25) afirma que los dos trazos que sobresalen del peinado pudieran ser plumas o, también, las orejillas de un casquete o gorro. Podría entroncarse entonces con los llamados «tocados de dos orejitas" definidos para otros conjuntos (GALIANA, M.F. 1985a: 61), cuya característica definitoria más sobresaliente es el estar integrados por dos apéndices cortos, más o menos anchos, separados entre sí y con una base amplia.

Por nuestra parte nos inclinamos a aceptarlo como un tocado de dos plumas y no como uno de estos tocados de dos orejitas debido sobre todo a lo relativo del criterio de diferenciación seguido para uno $u$ otro caso. El que la base de los apéndices sea más o menos ancha estará determinada por varios hechos, pero fundamentalmente y desde el punto de vista del espectador de las pinturas, vendrá determinado por la mayor o menor inserción que la pluma tenga sobre el cabello o en su caso, sobre la diadema.

Si la diadema, comentada anteriormente, servía como base para el engarce de otros elementos como son estos, las combinaciones que podemos encontrar son infinitas. Podemos situar las plumas en forma de $V$ detrás de la cabeza en la nuca, o colocar una pluma a cada lado de la cabeza, por ejemplo, y aunque la forma que nosotros percibimos será diferente, no por ello dejará en ambos casos de ser un tocado de dos plumas. La separación de los apéndices no es pues un criterio concluyente por sí mismo para hablar de un tipo de tocado u otro, de igual manera que tampoco lo es el que la base de estos apéndices sea más o menos ancha. Como ya hemos apuntado, la anchura de esa base estará en función de la porción de pluma que quede libre y que nosotros veamos, lo cual estará a su vez determinado por la tipología del peinado y por la cantidad de pluma insertada en el cabello o, en su caso, en la diadema.

Por estas razones pensamos que el arquero de la Cañaica del Calar de Moratalla muestra un tocado de dos plumas, situadas a cada lado de la cabeza y sujetas quizás por una de estas diademas, que al mismo tiempo obliga a un abultamiento del cabello en la parte de la nuca.

Los tocados de plumas, escasos en los conjuntos murcianos, se asocian exclusivamente a figuras masculinas. La actividad desarrollada por 
estos personajes, todos armados con arcos y flechas, es variada, apreciándose también una relación entre esa actividad y cada variante de tocado. Así, los dos individuos ataviados con tocados de una sola pluma se inscriben en un contexto de enfrentamiento bélico, mientras que el único arquero que lleva un tocado de dos plumas aparece en una composición de caza. No obstante lo reducido del material con que contamos nos obliga a ser prudentes a la hora de extraer conclusiones de este tipo.

- Tipo III. ${ }^{\circ}$ : Varillas

Denominamos varillas a unos trazos cortos y delgados presentes en algunas figuraciones formando parte del adorno de la cabeza, cuya función debió ser muy similar a la de la diadema, es decir, recoger y sujetar el cabello. Se localizan en sendas figuras femeninas del abrigo $10^{\circ}$ de la Fuente del Sabuco (Moratalla) y del conjunto de La Risca (Moratalla) (fig. 6, núm(s). 8-9). En ninguno de los dos casos parece que debamos interpretarlos como tocados de plumas, ya que su tipología en poco se asemeja a la de éstos, sobre todo si tenemos en consideración que en el mismo abrigo de la Fuente del Sabuco hay dos figuras con tocados de plumas, cuya lectura está clara y que no guardan relación alguna con estos trazos a los que hacemos referencia.

Para la fabricación de estas varillas pudo emplearse material variado, desde hueso o madera hasta metal.

- Tipo IV.: Pendientes

Este tipo de adorno de cabeza aparece en una figura femenina del abrigo $1 .{ }^{\circ}$ de la Fuente del Sabuco (Moratalla) (fig. 6, núm. 8). Los hemos denominado un tanto convencionalmente como pendientes por el lugar en el que se ubican, muy próximos a las orejas, marcadas por un ensanchamiento lateral de la cabeza. Por lo alargado de los trazos pintados resulta difícil dilucidar si se trata de simples lazos o de alguna otra clase de objeto fabricado en madera, hueso u otro material.

\section{- Tipo V.: Máscaras}

Sin llegar a ser frecuentes, se puede rastrear en diversos conjutos a personajes ataviados con tocados en forma de animal (BLASCO, M. C. 1974: 55) o con rasgos zoomorfos, hocico, cuernos o pico de pájaro, que hacen pensar en el simulacro de un animal (GalianA, M. F. 1985a: 62), hablándose de elementos de caza para los primeros y de máscaras para los segundos.

En los conjuntos murcianos hallamos a dos individuos a los que se les ha exagerado notablemente el trazo que simularia la nariz, lo que nos lleva a considerar este rasgo, en cierto modo, como la representación de 
una de estas máscaras. Se localizan en los conjuntos del Abrigo del Milano (Mula) y del Abrigo del Mojao (Lorca) (fig. 6, núm(s) 3 y 10), dándose la circunstancia de que ambos personajes son cazadores, por lo que el carácter de esa supuesta máscara como ardid de caza se refuerza un tanto.

\section{B.2. Adorno de Brazos}

La presencia de adorno en las extremidades superiores tan sólo la hemos podido constatar en los conjuntos de la Risca (Moratalla) y los abrigos del Barranco de los Grajos (Cieza). Se trata en los dos casos del mismo tipo de adorno consistente en apéndices largos y delgados entroncados en la figura que los lleva a la altura del codo, bien en los dos brazos o en uno sólo.

Compartimos la interpretación de que se trata de cintas colgantes (GALIANA M. F. 1985a), para cuya fabricación debió utilizarse cuero y otra clase de elemento vegetal. En este tipo que podemos denominar genéricamente como lazos o cintas podemos apreciar ciertas variantes. La variante "a" la formaría este adorno cuando está compuesto por una sola cinta (fig. 6, núm. 12). La variante «b» la forman tres cintas (fig. 6, núm. 1) y la variante " $\mathrm{C}$ " la observamos cuando contamos con cuatro de estos lazos (fig. 6, núm. 11).

Todos ellos se asocian a figuras femeninas y en ningún caso hay una repetición de variantes dentro de una misma figura, de tal manera que las combinaciones que constatamos son la Variante "a" sóla, la variante "a" junto con la "b", cada una en un brazo distinto, y la variante "a" con la variante "C». Indicar también que en la figura del conjunto del Barranco de los Grajos (Cieza) el lazo no entronca con el brazo por el codo sino más arriba, en una zona intermedia entre ese codo y el hombro. No creemos, en cambio, como se ha apuntado (GalIANA, M. F. 1985a: 66) que estos lazos arranquen directamente de la axila.

\section{VESTIDO}

A pesar de que podemos suponer que una gran parte de las figuras representadas están desnudas, para el resto de ellas, para las que si podemos intuir una indumentaria básica, variada de otro lado, es posible establecer una serie de tipos a partir de los cuales habrá que relacionar las distintas variantes.

\section{- Tipo 1.: Pantalón ancho}

Exclusivo de las figuras masculinas, es un pantalón ancho que llega hasta por debajo de las rodillas. El único ejemplo localizado en los frisos 


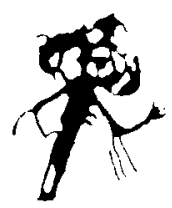

1

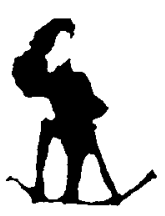

5

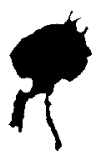

9

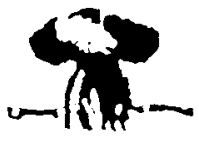

2

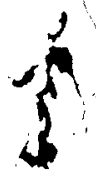

6

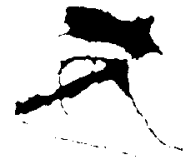

10

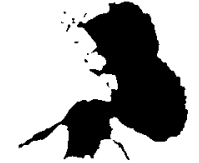<smiles>C[As](C)(C)C</smiles>

4

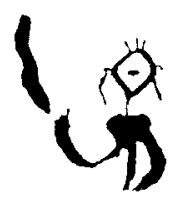

8
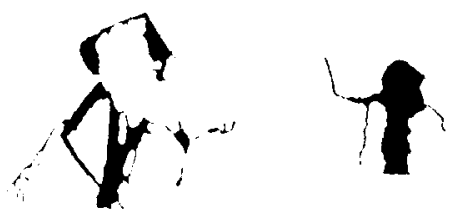

11

12

Fig. 6. ADORNO: 1. La Risca (LILLO-LILLO, 1979); 2-3. El Milano (SAN NiCOLAS et alii 1988); 4. LOS Grajos (BELTRAN, 1969); 5-6. Fuente del SabuCo (BELTRÁN, 1972); 7. Cañaica del Calar (BELTRÁN, 1972); 8. Fuente del Sabuco (BELTAÁN, 1972); 9. La Risca; 10. El Mojao; 11. La Risca (LILLO-LILLO, 1979); 12. Los Grajos (BELTRÁN. 1969).

naturalistas murcianos se encuentra en la Cueva del Humo, dentro de la Peña Rubia de Cehegín, recordándonos mucho a los pantalones «clásicos" que vemos en otros conjuntos (fig. 7 , núm. 1). No obstante, el estilo particular que afecta a las pinturas cehegineras (BELTRÁN, A. et alii, 1985), con una tosquedad manifiesta en el trazo, confiere esa misma troquedad a esta prenda, hasta el punto de mostrar diferencias entre las propias piernas, llegando una hasta la rodilla y sobrepasándola en la otra.

- Tipo II. ${ }^{\circ}$ : Pantalón ancho y corto

Propio también de figuras masculinas, se trata de un pantalón ancho y corto que llega hasta medio muslo, si alcanzar la rodilla (fig. 7 , núm(s). 2-5). En algún caso concreto, sobre todo cuando la figura se encuentra representada de perfil, da la sensación de que es una prenda talar, del tipo de una túnica, como sucede con algunos individuos del conjunto del Barranco de los Grajos (Cieza) (fig. 7, núm. 3). 
Al analizar la vestimenta de las figuras femeninas el mayor problema se plantea a la hora de saber si se trata de vestidos completos o, como parece, de faldas que dejarian el pecho al descubierto. Para F. Jordá (1966; 1974) no hay duda de que se trata de faldas mientras que A. Beltrán (1966) no sólo las acepta como tales sino que utiliza estas faldas como criterio básico a tener en cuenta para señalar diversos tipos de representaciones femeninas.

Ciertamente, se hace dificil discernir en la mayor parte de las figuras si se trata de vestidos completos o de faldas. La única evidencia con que contamos es la representación marcada de los pechos en muchas de estas figuras, los cuales se muestran muy colgantes, como carentes de sujeción (GaLIANA, M. F. 1985a: 71) lo que conduce a pensar que estamos ante faldas y no ante vestidos, al menos en aquellas figuras en las que se aprecia este detalle.

Atendiendo a la clasificación que hemos establecido podemos diferenciar varios tipos:

\section{- Tipo III. ${ }^{\circ}$ : Vestido largo}

Con carácter excepcional estaríamos ante la representación de un vestido completo, que cubriría desde el cuello hasta el muslo. Sería un vestido largo ajustado al cuerpo y con los extremos poco anchos (fig. 7, núm. 6).

El problema que se plantea es saber si estamos ante una representación masculina o por el contrario, se trata de una mujer. Los autores que estudiaron las pinturas del Abrigo del Milano de Mula, en el que se localiza esta representación la aceptaron como tal figura femenina, sobre todo en virtud a ciertas semejanzas con otra figuración de sexo claramente definido del conjunto de Minateda (Albacete) (SAN NiCOLÁs, M. et alii, 1988: 344).

Por nuestra parte, consideramos como factor determinante a la hora de aceptarla como una representación femenina el distinto tratamiento que presenta en relación al arquero situado a su izquierda. Mientras este aparece desnudo, algo común entre los personajes masculinos dentro del Arte Naturalista, esta otra figura va cubierta con una prenda que le cubre todo el cuerpo.

- Tipo IV.: Faldas

Englobamos en este tipo todas aquellas representaciones de faldas, entre las cuales es posible establecer varios subtipos.

- Subtipo 1: Falda acampanada con picos salientes 
La falda muestra formas rerdondeadas, con los extremos sobrepasando el borde inferior de la misma, de tal manera que en esta parte la vestimenta adquiere la forma de una " $V$ » invertida (fig. 7 , núm(s). 7-10), con los extremos redondeados.

Una variante podría venir determinada por un tipo de falda acampanada, de formas redondeadas, en la que los extremos no sobresalen (fig. 7, núm 11). Se localizan en los conjuntos de La Risca (Moratalla) y del Barranco de los Grajos (Cieza).

\section{- Subtipo 2: Falda triangular.}

Son faldas en las que dominan las líneas rectas, dando ese aspecto triangular a la misma al ser muy anchas en su base (fig. 7, núm. (s). 12 17). Es posible establecer diversas variantes dentro de este subtipo general. La variante a sería una falda triangular en la que los picos laterales se desarrollan bastante, sobresaliendo de ese esquema triangular (fig. 7, núm. 12). La variante b estaría formada por aquellas faldas triangulares que presentan sus extremos redondeados (fig. 7, núm(s). 15-16) y por último, la variante c sería aquella en la que, aún manteniendo la forma triangular común a todas ellas, hay también una leve convexidad en sus trazos laterales (fig. 7, núm. 17).

\section{- Subtipo 3: Falda globular.}

Es un tipo de falda muy amplia que cubre desde la cintura hasta los tobillos en donde se ciñe ostensiblemente, confiriendo un aspecto globular marcado. La única representación, de carácter femenino, que hemos documentado ataviada con esta indumentaria se localiza en la Cueva de las Palomas, dentro del conjunto de la Peña Rubia de Cehegín (fig. 7, núm. 18).

Junto a estos tipos más o menos generalizados entre los diversos frisos pintados, habría que considerar algunos otros tipos catalogables como excepcionales. Es el caso de una figura femenina del abrigo $1 .^{\circ}$ de la Fuente del Sabuco (Moratalla), que presenta un vestido completo pero indicado tan sólo por su contorno exterior, de tal manera que se observa el cuerpo y las piernas del personaje representado. Es como si la prenda hubiese estado confeccionada con un tipo de tela transparente (fig. 7), núm. 19). Esta figura fue estudiada por M. ${ }^{a}$ F. ${ }^{a}$ Galiana (1985a: 72), si bien pensó que se trataba solamente de una falda y no de un vestido completo, hecho que queda reflejado inequívocamente por el trazo curvo de la parte delantera de la figura.

Otra representación particular es la de una mujer existente en ese mismo conjunto de la Fuente del Sabuco vestida con una falda larga, que 
cubre desde la cintura hasta los tobillos, dejando visibles los pies, pero muy ajustada, con un diámetro que va paulatinamente reduciéndose hacia la parte inferior de la misma (fig. 7, núm. 20)

Resulta complicado precisar el tipo de material empleado para la fabricación de todas estas indumentarias que hemos descrito. Este podría variar desde las pieles de animales hasta tejidos como el lino o la lana. Para F. Jordá (1974: 209-223) la mayoría estarian fabricados en tela, cuero, o incluso en trenzados de cuerda, por una "industria" textil doméstica.

Por otro lado, podemos aceptar el empleo de la piel para algunos de los tipos de vestidos propuestos, como puedan ser las faldas triangulares, excepto algunas variantes como la de picos salientes, pero para otros tipos la utilización de la piel de animales no parece lo más adecuado, ya que por su rigidez no permite el vuelo y la amplitud que algunas de estas prendas reflejan. Para las faldas acampanadas o las globulares es preciso otro tipo de tejido como podría ser la lana o el lino, bastante más flexible que las pieles.

Mención especial requiere una figura del conjunto muleño del Abrigo del Milano (fig. 7, núm. 6), provista de un vestido largo, completo, marcado por una serie de líneas verticales. Ello quizá responda, como también advirtieron los autores que estudiaron estas pinturas (SAN NICOLÁS, M. et alii 1988) a un intento por señalar algún tipo concreto de tejido o técnica textil. Pudiera tratarse de la técnica del trenzado de cuerda apuntada por F. Jordá (1974: 220), aunque él mismo considera que las franjas verticales indicadas en algunas figuras, entre las que tal vez habría que incluir esta, obedece más bien a franjas de tela cosidas la una con la otra, lo que vendría impuesto por la poca anchura de la tela obtenida en los telares a mano, que suelen ser estrechos.

En lo que se refiere a la distribución de tipos según la actividad de quienes los llevan, observamos como el Tipo l. ${ }^{\circ}$ es utilizado por cazadores; el Tipo $11 .{ }^{\circ}$, por danzarines y cazadores; el Tipo $111 .{ }^{\circ}$ aparece en una figura sin actividad determinada mientras que en el Tipo IV. ${ }^{\circ}$ hay una variedad manifiesta en función de los subtipos definidos. El subtipo 1 se da en bailarinas y en figuras sin actividad clara; el subtipo 2 es empleado también por bailarinas y por figuras femeninas que sin actividad aparente están inmersas en un contexto de enfrentamiento bélico y el subtipo 3 se da en una figura femenina sin actividad determinada.

\section{PEINADOS-CABELLERAS}

Consideramos como peinado o cabellera el tratamiento exclusivo del cabello, probablemente con finalidad de ornato, en la que no participa 


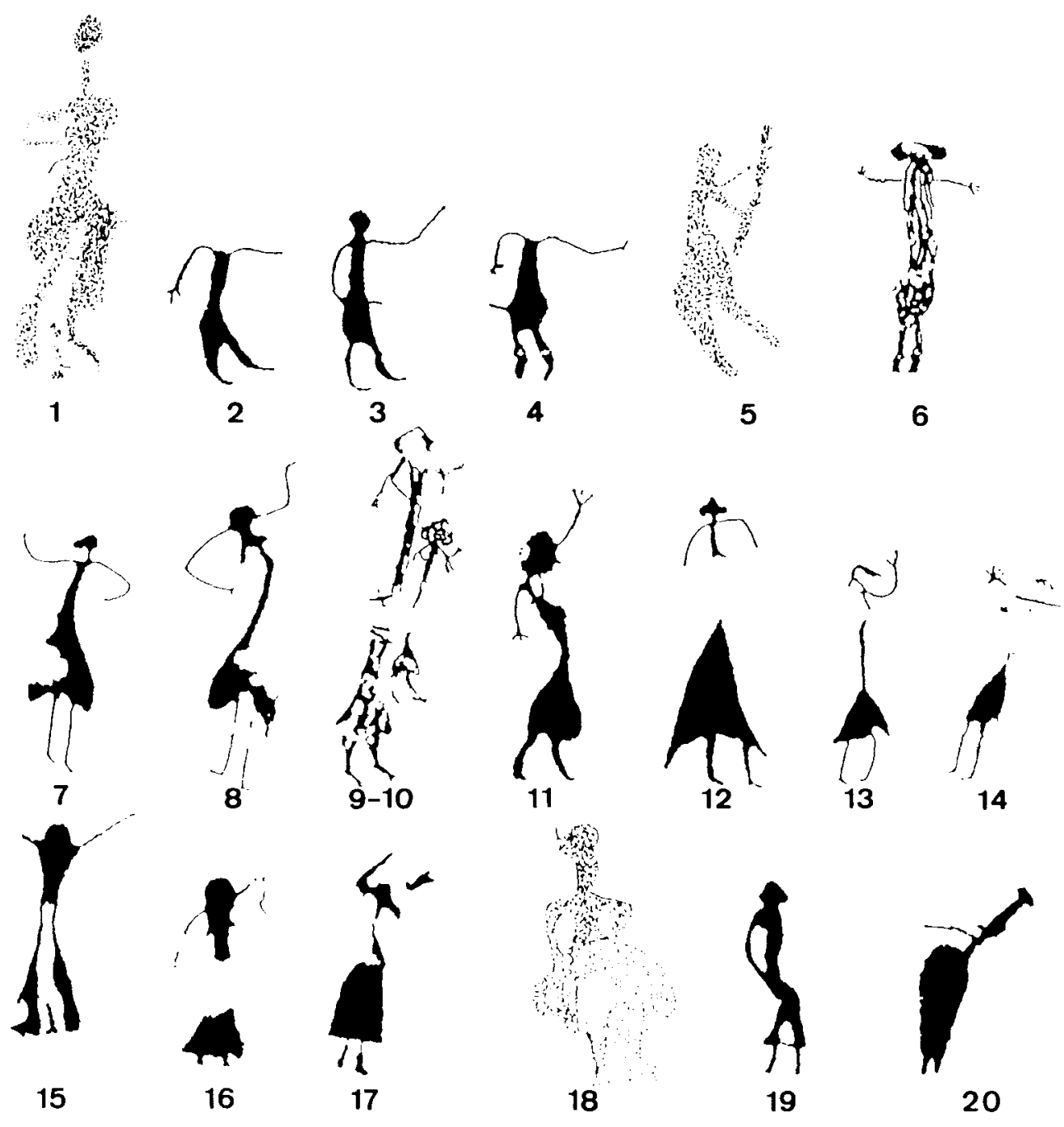

Fig. 7. VESTIDO: 1. Peña Rubia (BELTRAN-SAN NiCOLAS, 1988); 2-4. Los Grajos (BELTRÁN 1969); 5. Peña Rubia (BELTRAN-SAN NiColás, 1988); 6. El Milano (SAN NICOLAS et alii 1988), 7-8. LOS Grajos (BELTRAN, 1969); 9-10. La RisCa (LILLO-LILLO. 1979); 11-16. Los Grajos (BELTRAN, 1969); 17. Fuente del Sabuco (BELTRÁ, 1972); 18. Peña Rubia (BELIRÁN-SAN Nicolás, 1988); 19-20. Fuente del Sabuco (BELTRAN. 1972). 
ningún otro elemento más con la función de adorno, en cuyo caso, como señalamos anteriormente, preferimos hablar de "tocado».

Asimismo, hemos hablado de las diademas y de las varillas como objetos de adorno de cabeza. Los incluíamos en ese apartado por simple comodidad a la hora de estructurar el material disponible, pero comentábamos también como dichos objetos tienen un carácter más funcional que de adorno. Se emplean para configurar un tipo concreto de peinado más que para adornar por sí mismos, ya que en realidad en la mayoria de las ocasiones el cabello ocultaría, a tenor de las formas pintadas, a la misma diadema o a las varillas.

Atendiendo a la forma hemos establecido los siguientes tipos de cabelleras:

-- Tipo 1. : Melena

El cabello se presenta a modo de larga melena suelta, sin ningún elemento de sujeción (fig. 8, núm. 1). Lo hallamos en un cazador lanzado a la carrera del conjunto lorquino del Abrigo del Mojao.

\section{-Tipo II.: Cabellera bilobulada}

El cabello se manifiesta a modo de dos masas circulares unidas, dando ese aspecto bilobulado. (fig. 8, núm. 2). Este tipo está representado en un cazador del conjunto de la Cueva-sima de la Serreta I de Cieza.

-Tipo III. : Cabellera trilobulada

El peinado adopta una forma clara de trilóbulo, con tres masas circulares, una central que podría ser la cabeza, y dos laterales formadas por el cabello en sí (fig. 8, núm(s). 3-4). Lo observamos en dos figuras femeninas de los conjuntos del Barranco de los Grajos (Cieza) y de la Fuente del Sabuco (Moratalla), y a tenor de estas representaciones podemos establecer dos variantes distintas dentro del tipo general. La variante "a» presenta las dos masas laterales a una misma altura formando sus bases una línea horizontal (fig. 8, núm. 3), mientras que en la variante «b» esas masas laterales se proyectan hacia abajo rompiendo esa horizontalidad. Parece como si al desplazarse cubriera parte del cuello de la figura (fig. 8: núm. 4).

\section{-Tipo IV. : Peinado triangular}

Se trata de un peinado de aspecto triangular, en el que podemos distinguir a su vez dos subtipos:

-Subtipo 1. Los vértices del triángulo, sobre todo los laterales, están muy marcados (fig. 8, núm. 5). 
-Subtipo 2. Es una forma triangular con las esquinas romas, ligeramente redondeadas (fig. 8, núm(s). 6-9). Dentro de este subtipo podemos establecer también dos variantes. La variante "a» presenta en el triángulo descrito una altura semejante o superior a la anchura de su base (fig. 8 , núm(s) 6-8), mientras que en la variante «b» la altura es claramente inferior a la longitud de esa base (fig. 8, núm. 9).

Este tipo de peinado triangular, en sus diversos subtipos y variantes, to hallamos en los conjuntos de La Risca (Moratalla), la Fuente del Sabuco (Moratalla), el Barranco de los Grajos (Cieza) y en el Abrigo del Milano (Mula).

\section{- Tipo V. : Peinado elíptico}

A partir de la forma típica elíptica de este Tipo (fig. 8, núm(s). 10-11), podemos establecer una variante "a» en la que se aprecia una ligera tendencia a la forma circular (fig. 8, núm. 11). Este tipo de peinado lo documentamos en los conjuntos de la Fuente del Sabuco (Moratalla) y del Abrigo del Milano (Mula).

\section{-Tipo VI. : Peinado en trapecio invertido}

La cabellera adopta esa forma de trapecio invertido, con los extremos superiores muy salientes (fig. 8, núm. 12). Tan solo 10 hemos observado en una figura masculina del conjunto ciezano del Barranco de los Grajos.

-Tipo VII. : Moño

En esta clase de peinado que hemos dado en llamar como "moño", la mayor parte del cabello se dispone en la parte posterior de la cabeza, en torno a la nuca, para lo cual contaría con algún tipo de elemento de ayuda como sería una diadema o un simple lazo o cinta, que aglutinase de esa forma el cabello (fig. 8, núm. 13). Lo documentamos en la representación de un arquero del conjunto del Abrigo del Milano (Mula).

-Tipo VIII. : Cabellera circular

La cabellera presenta una clara forma circular, si bien en ocasiones y debido a las actitudes de los personajes que las muestran se observa solamente la mitad de ésta, de tal manera que a efectos descriptivos podríamos considerarlos como una variante «a" en la que el cabello se dispone en una forma semicircular (fig. 8, núm(s). 14-21). Constatamos este tipo de peinado en los conjuntos de la Fuente del Sabuco (Moratalla), los abrigos del Barranco de los Grajos (Cieza) y en la Cueva del Humo de la Peña Rubia (Cehegín).

-Tipo IX. : Peinado ovoide. 
La cabeza, junto con el cabello, muestra una forma muy desarrollada en altura y a la vez estrecha, como si se tatase de una forma ovoide (fig. 8, núm(s). 22-24). Lo documentamos en la Cueva del Humo y en la Cueva de las Palomas, dentro del conjunto de la Peña Rubia de Cehegín.

\section{-Tipo X. : Peinado alto}

Denominamos como peinado alto a aquel en el que es posible diferenciar, por un lado, la cabeza del individuo propiamente dicha y por encima de ésta y claramente delimitada, la cabellera.

Asimismo, establecemos varios subtipos dentro de este peinado alto:

- Subtipo 1. La masa que sugiere el cabello presenta una forma redondeada (fig. 8, núm(s). 25-28).

- Subtipo 2. La forma de la masa del cabello es de tendencia rectangular (fig. 8, núm. 29).

El peinado alto lo documentamos en los conjuntos de la Peña Rubia de Cehegín y los Abrigos del Buen Aire de Jumilla.

Relacionando los Tipos establecidos con el sexo de las figuras estudiadas, hallamos que propios de figuras masculinas son los tipos $1 .^{\circ} 11 .^{\circ}$, $\mathrm{V} I^{\circ}$, VII..$^{\circ}$ y $I X .^{\circ}$. El Tipo $11 .^{\circ}$ es exclusivo de figuras femeninas y el resto, Tipos IV. ${ }^{\circ}, V^{\circ}, V_{I I I} .^{\circ}$ y $X .^{\circ}$ se dan indistintamente en figuras masculinas y femeninas.

Si la relación la establecemos entre los peinados y la actividad desarrollada por los distintos personajes que los llevan, podemos determinar que las bailarinas y danzantes, de ambos sexos, están asociados con los Tipos III. ${ }^{\circ}$, IV. ${ }^{\circ}$, VI. ${ }^{\circ}$ y VIII..$^{\circ}$. Los guerreros muestran los Tipos III. ${ }^{\circ}$, IV. ${ }^{\circ}, \mathrm{V} .{ }^{\circ}$ y VIII. ${ }^{\circ}$, y los cazadores los Tipos $1 .^{\circ}, 11 .^{\circ}$, VII. ${ }^{\circ}$, IX..$^{\circ}$ y X..$^{\circ}$.

\section{ASPECTOS CRONOLÓGICOS}

La relación de los diferentes rasgos etnográficos definidos con los elementos propios de la cultura material permitirá estrechar los límites cronológicos para las pinturas, cuestión que, admitámoslo, sigue siendo el principal caballo de batalla en los estudios sobre arte rupestre prehistórico.

En el grupo de las armas, los restos materiales de arcos convexos más antiguos han sido hallados en Homelgaard (Dinamarca) y en Wiss (Cuenca del Petchora), fechados entre el 6000 a C. y el 6100-5100 a C., respectivamente (JORDA, F. 1980: 89). Un arco completo de $1,30 \mathrm{mts}$ de 


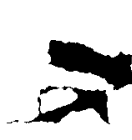

1

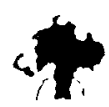

7

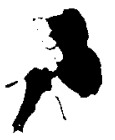

13

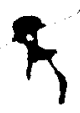

19

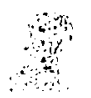

25

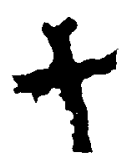

2

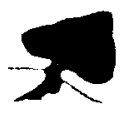

8

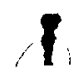

14

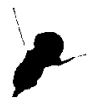

20

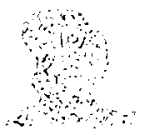

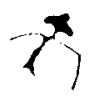

3

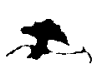

9

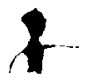

15

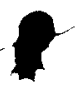

21

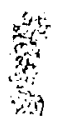

27

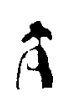

4

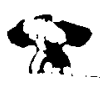

10

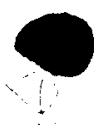

16

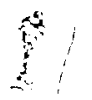

22

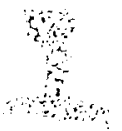

28

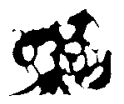

6
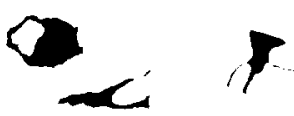

12

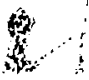

18

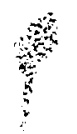

23

24

Fig. 8. CABELlERAS-PEINADOS: 1. El Mojao; 2. La Serreta (Mateo Saura, 1992); 3. LoS Grajos (BELTRÁN, 1969); 4. Fuente del Sabuco (BELTRÁN, 1972); 5. Los Grajos (Beltran, 1969); 6-7. La Risca (LILlo.LILLO, 1979); 8. El Milano (SAN NI. COLAS et alii 1988); 9. Fuente del Sabuco (BELtRÁN, 1972); 10. El Milano (SAN Nicolás et alii 1988); 11. Fuente del Sabuco (BELTRÁN, 1972); 12. LOS Grajos (BeltRÁn, 1972); 13. El Milano (SAN Nicolás et alii 1988); 14-15. Los Grajos (BELtRÁN, 1969); 16-17. Fuente del Sabuco (BeLtRán, 1972); 18. PeÑa RuBia (Beltrán-SAN Nicolás, 1988); 19-21. Los Grajos (BELTRÁN, 1969); 22-24. Peña Rubia (BeltaÁn-San Nicolás, 1988); 25-26. Buen Aire; 27-29. Peña Rubia (Beltran-San NICOLÁS, 1988).

longitud de vara fue localizado en el poblado de Les Baigneurs, en Isère (Francia), perteneciente a la "Civilización Saône-Rhone" y datado en el 2700 a C. (BocQuet, A. et alii, 1982: 18). Asimismo, restos de arcos biconvexos se han hallado también en contextos epipaleolíticos, concreta- 
mente en Wiss y en Braband (Dinamarca), este último dentro de la "Cultura Erteböllense" (JORDA, F. 1980: 89).

Paralelos figurativos, siempre más discutibles, se pueden establecer con el Mediterráneo Oriental, con pinturas de los Niveles VII. ${ }^{\circ}$ y III. ${ }^{\circ}$ del Santuario de Çatal-Hüyück (Anatolia). El Nivel VII. ${ }^{\circ}$ se fecha en el 6200$6050+/-100$ a.C. (JORDA, F. 1980:88) y el Nivel 111. ${ }^{\circ}$ entre 5790-5750 a.C. (MellaArt, J. 1971: 52). También se podrian relacionar con las representaciones de arcos convexos del Arte esquemático ibérico (AcOSTA, P. 1968) y con las estelas decoradas del Suroeste peninsular, lo que nos llevaría a contextos de Bronce Final y 1. ${ }^{a}$ Edad del Hierro (Almagro, M. 1966; VARELA, M. et alii 1977). Representaciones de arcos biconvexos hay en el Nivel VIII ${ }^{\circ}$ de Çatal-Hüyück fechado en 6280-6200 a. C. (MellaART, J. 1971: 52) y en una estela decorada del Suroeste (ALMAGRO, M. 1966; ALMAGRO GorbeA, M. 1977).

En lo que se refiere a las flechas, centrándonos en los tipos establecidos, observamos una amplitud cronológica muy marcada.

El Tipo $\|^{\circ}$, de "tendencia romboical o foliácea", está presente en la cuencia mediterránea occidental desde el IV milenio a.C. (GaLIANA, M.F. 1985 b: 26), mientras que en los niveles del Neolítico final de la Cueva de l'Or (Beniarrés, Alicante) (MARTI, B. et alii 1980: 297) también se ha documentado este tipo de punta. Proliferan durante el Eneolítico y los encontramos tanto en cuevas sepulcrales, caso de la propia Peña Rubia de Cehegín (Murcia) (Beltrán, A. et alii 1988) como en poblados al aire libre, caso del Poblado de La Salud, en Lorca (Murcia). Modelos en metal los hay desde el Eneolítico Campaniforme (DELIBES, G. 1977), son las denominadas "Puntas Palmela», que perviven hasta el Bronce final (BLAN. CE, b. 1971: 148). Asimismo, en poblados argáricos ha aparecido esta clase de punta y entre ellos podemos destacar La Bastida de Totana (Murcia) (MARTínez, J. et alii 1947) o Ifre, en Lorca (SIRET, et alii 1980), ambos del Bronce medio.

El Tipo $1 \mathrm{II}^{\circ}$, "punta de forma triangular", se desarrolla desde la transición del Neolítico final al Eneolítico y perdura durante la Edad del Bronce, período en el que ocupa un puesto destacado (LULL, V. 1983: 218). Los paralelos figurativos podrían llevarse hasta la l. ${ }^{a}$ Edad del Hierro, ya que representaciones similares se encuentran en las estelas decoradas del Suroeste, fechadas, como ya hemos indicado, en los siglos $I \mathrm{X}^{\circ}-\mathrm{VIII^{ \circ }}$ a C. (Almagro, M. 1966; Varela. M. et alii 1977).

Para el Tipo IV $\mathrm{V}^{\circ}$, que hemos denominado en "T transversa", no hemos documentado paralelo alguno, ni mueble ni figurativo, y no creemos que se pueda relacionar con las "puntas de diente de arpón" de F. Jordá 
(1975: 221), que fecha en la Edad del Hierro, en torno al siglo VII a C., estando elaborada, claro está, en metal.

Acerca de los vástagos de flecha, ya hemos apuntado la existencia en la Cueva del Peliciego de Jumilla (Murcia) de 74 restos, de sección variada y fechados en el Eneolítico de la zona (Molina, $M^{a}$ et alii 1973).

Para las hachas, si son de piedra las representadas en los distintos abrigos con arte, podemos suponer una cronología muy amplia, desde el Neolítico hasta la Edad del Bronce. Si son elaboradas en metal, ésta cronología arrancaría sobre todo desde el Bronce medio.

Así pues, por lo que respecta a las armas, y atendiendo a los paralelos muebles, los testimonios más antiguos se remontan a finales del $\mathrm{VII}^{\circ} \mathrm{mi}$ lenio a $\mathrm{C}$. para los arcos y al IV ${ }^{\circ}$ milenio para las flechas, aunque es lógico pensar en una cronología similar para estas últimas que la existente para los arcos, por tanto, desde el Epipaleolítico. Los paralelos figurativos también se remontan al $\mathrm{V}^{\circ}{ }^{\circ}$ milenio a.C. en el Mediterráneo Oriental, llegando hasta los siglos $\mid \mathrm{X}^{\circ}-\mathrm{VIII^{ \circ }}$ a $\mathrm{C}$.

Acerca de los recipientes, la imposibilidad de determinar el material en que estaban elaboradas hace difícil precisar su cronología. Probablemente, los carcajes, únicos recipientes identificados en los conjuntos de arte murcianos, estuviesen fabricados con esparto o cuero, que por su flexibilidad y poco peso facilitan el transporte. Si son de cuero, su empleo no conlleva una cronología concreta, ya que se emplea en todos los tiempos prehistóricos (GalianA, M.F. 1985a: 80), mientras que si son de esparto, las evidencias halladas de este material nos conducen por ahora a ambientes eneolíticos y posteriores (MUÑOZ, A.M. 1982; NAVARRO, J.F. 1983), si bien, por sus propiedades, su utilización debió ser muy anterior.

El adorno se presenta como algo particular de cada pueblo y por ello, fijar una cronología en función del mismo resulta cuanto menos arriesgado, sobre todo si tenemos en consideración que se suele recurrir a unos elementos muy concretos para emplearlos como adorno por parte de los diversos pueblos que podamos analizar. A la hora de buscar paralelismos, figurativos en su gran mayoría, podemos caer en el error de hacer sincrónicas o simplemente relacionar entre sí, a representaciones dotadas de un mismo detalle ornamental, entre las que la única relación es el empleo de un mismo convencionalismo. Las plumas, por ejemplo, son utilizadas de manera universal como elemento de adorno corporal y no por ello establecemos vínculos entre todos aquellos grupos humanos que las usan.

De las diademas sólo conocemos testimonios metálicos, como son las campaniformes de Montilla, Alcalá o Matarrubia (MALuQueR, J. 1970: 84- 
86) O ya argáricas como las del Cabezo Redondo de Villena (Alicante) (Almagro GorbeA, M. 1974: 89). En cambio, si estas diademas hubieran sido confeccionadas con otros materiales como el trenzado de esparto 0 el cuero, su cronología se retrasaría bastante.

De lo que hemos interpretado como varillas, alcanzan una gran difusión durante el período Eneolítico, siendo fabricadas en hueso principalmente, aunque también se constatan en la etapa anterior neolítica (GARCíA DEL TORO. J.R. 1985b).

Del resto de elementos de adorno observados en las representaciones, pendientes, máscaras o lazos, tan sólo podemos señalar su carácter atemporal.

Sobre el vestido podríamos precisar un poco su cronología si conociésemos el material con que estaban hechos. Si se trata de piel animal, son atemporales, mientras que si fuesen de lana o lino, los testimonios de dicha actividad como son las pesas de telar, etc., los situaría en la Edad del Bronce. No obstante, se puede documentar una industria textil anterior y prueba de ello es el vestido, casi completo, elaborado con lino que fue hallado en el ajuar de Cueva Sagrada I de Lorca (Murcia) (AYALA, M.M. 1987). Este yacimiento ha dado una fecha de C14, obtenida sobre 75 gramos de esparto de ese mismo ajuar, de $3879+/-100$ B.P. (EIROA, J.J. 1990), que lo sitúa en el Eneolítico de la zona.

En definitiva, los límites cronológicos en que podemos situar a los diferentes aspectos etnográficos definidos los constituyen el Epipaleolítico y la Edad del Bronce e, incluso, para algunos casos muy concretos se podría llegar hasta la Edad del Hierro. Para aquellos elementos para los que tenemos paralelos materiales, entre los que sobresalen los arcos y las flechas, hay una tendencia a retrasar su cronología hacia el límite inferior epipaleolítico.

No cabe duda de que estas referencias apuntadas por los rasgos etnográficos no resuelven el problema de la cronologia del Arte Rupestre Naturalista, pero constituyen un elemento más con el que contar en nuestros estudios. Éstos, junto a otros varios aspectos, como son los rasgos socio-económicos contenidos en las pinturas, o los depósitos arqueológicos existentes en algunos de los abrigos con arte, permitirán ir perfilando cada vez más la entidad cronológico-cultural de los autores de este arte.

\section{BIBLIOGRAFIA}

Acosta, P. (1968): La pintura rupestre esquemática en España. Salamanca, Universidad de Salamanca, 250 páginas, 60 figuras y 22 mapas 
Almagro Basch, M. (1956): “Las pinturas del Bajo Aragón", Prehistoria del Bajo Aragón. Zaragoza, Instituto de Estudios Turolenses de la Excma. Diputación Provincial de Teruel, 159 páginas y 110 láminas.

- (1966): "Las estelas decoradas del Suroeste peninsular", Bibliotheca Praehistorica Hispana, VIII. Madrid, C.S.I.C., 215 páginas, 199 figuras y 78 láminas.

Almagro Gorbea. M. (1974): “Orfebrería del Bronce final en la Peninsula Ibérica. El Tesoro de Abiá de la Obispalía; la orfebrería Tipo Villena; los cuencos de Axtrokim, Trabajos de Prehistoria, 31. Madrid, Centro de Estudios Históricos, C.S.I.C., págs. 39-100

- (1977): "El Bronce final y el periodo Orientalizante en Extremadura", Bibliotheca Praehistorica Hispana, XIV. Madrid, C.S.I.C., 253 páginas, 81 figuras y 50 láminas.

Alonso, A.-Grimal, P. (1985): "Las pinturas rupestres de la Fuente del Sabuco II, (Moratalla, Murcia)", Ampúries, 47. Barcelona, Diputación de Barcelona, págs. 28-33, 4 figuras.

Ayala Juan, M.M. (1987): "Enterramientos calcolíticos de la Sierra de la Tercia, Lorca, Murcia. Estudio Preliminar», Anales de Prehistoria y Arqueología. Murcia, Universidad de Murcia, págs. 9-24.

Beltran Martinez. A. (1968): "Arte Rupestre Levantino", Monografias Arqueológicas, IV. Zaragoza, Universidad de Zaragoza, 258 páginas, 156 figuras.

- (1969): "La Cueva de los Grajos y sus pinturas rupestres en Cieza (Murcia)", Caesaraugusta, 31-32. Zaragoza, Diputación de Zaragoza, págs. 45-88, 31 figuras.

- (1972): "Los abrigos pintados de la Cañaica del Calar y de la Fuente del Sabuco, El Sabinar (Murcia)", Monografias Arqueológicas, IX. Zaragoza, Universidad de Zaragoza, 121 páginas, 100 tiguras.

- (1989): Ensayo sobre el origen y significación del arte rupestre prehistórico. Zaragoza, Universidad de Zaragoza, 199 páginas, con figs. y láminas.

Beltrán Martinez, A.; San Nicolás del Toro. M. (1988): Las pinturas de las Cuevas de la Peña Rubia. Zaragoza, Universidad de Zaragoza, 119 páginas, con figs. y láminas.

BlANCE, B. (1971): “Die Anfänge der metalurgie auf der Iberischen Halbinsel», Studien zur den Anfängen der metalurgie, 4. Berlín.

Blasco Bosquet, M ${ }^{\text {a }}$ C. (1974): "La caza en el arte rupestre del Levante español", Cuadernos de Prehistoria y Arqueologia, 1, Madrid, Universidad Autónoma de Madrid, págs. 29-55.

- (1975) : "La recolección en el arte rupestre levantino", Miscelánea que al profesor Beltrán dedican sus alumnos. Zaragoza, págs. $49-58$

- (1981): "Tipologia de la figura humana en el arte rupestre levantino", Altamira Simposium. Madrid, Ministerio de Cultura, págs. 361-377.

Bocquet, A.; Houot. A. (1982): “La vie au neolithique. Charavines, un village au bord d'un lac il y a 5.000 ans", Histoire et Archaéologie. Les dossiers, 64.

Delibes, G. (1977): "El vaso campaniforme en la Meseta Norte española», Studia Archaeologica, 46. Valladolid, Universidad de Valladolid, 176 páginas.

Elroa García. J.J. (1987): "Noticia preliminar de la 1. campaña de excavaciones en el Poblado de la Salud y en Cueva Sagrada I (Lorca). Murcia", Anales de Prehistoria y Arqueologia. Murcia, Universidad de Murcia, 3, págs. 53-76.

- (1990): “Dataciones absolutas del Poblado de la Salud y de Cueva Sagrada I (Lorca, Murcia)", Homenaje a J. Molina. Murcia, Academia Alfonso X "el Sabio", págs. 39-50.

Esteve Gálvez, F. (1974): "Probable significación de unas pinturas rupestres del Maestrazgo", Cuadernos de Prehistoria y Arqueología, I. Castellón, Diputación Provincial de Castellón de la Plana, págs. 9-18.

GalianA, $M{ }^{\text {a }} F^{a}$ (1985a): "Contribución al arte rupestre levantino: análisis etnográfico de las figuras antropomorfas", Lucentum, IV. Alicante, Universidad de Alicante, págs. 55-87.

- (1985b): "Consideraciones sobre el arte rupestre levantino: las puntas de flecha", El Eneolítico en el País Valenciano. Alcoy, Diputación Provincial de Alicante, págs. 23-33.

GARCIA DEL TORO, J.R. (1985a): "Nuevos abrigos con pinturas rupestres en el Barranco del Buen Aire (Jumilla). Informe preliminar". Anales de Prehistoria y Arqueologia, 1. Murcia, Universidad de Murcia, págs. 105-110.

- (1985b): "Las Ilamadas varillas de hueso en los enterramientos humanos colectivos del Eneolítico del Levante español. Tipologia morfotécnica e hipótesis funcional», El Eneolitico en el País Valenciano. Alcoy, Diputación Provincial de Alicante, págs. 157-164. 
JoRda Cerda. F. (1966): "Notas para una revisión de la cronologia del arte rupestre levantino", Zéphyrus, XVII. Salamanca, Universidad de Salamanca, págs. 47-76.

- (1971a): "Los tocados de plumas en el arte rupestre levantino", Zéphyrus, XXI-XXII. Salamanca, Universidad de Salamanca, págs. 35-72.

- (1971b): "Bastones de cavar, layas y arado en el arte rupestre levantino", Munibe, XXIII. San Sebastián, Sociedad de Ciencias Aranzadi, págs. 241-248

- (1974): "Formas de vida económica en el arte rupestre levantino", Zéphyrus, XXV. Salamanca, Universidad de Salamanca, págs. 209-223

- (1975a): Las puntas de flecha en el arte levantino", XIII Congreso Nacional de Arqueologia. Zaragoza, Universidad de Zaragoza, págs. 219-226.

- (1975b) : "La sociedad en el arte rupestre levantino", Papeles del Laboratorio de Arqueología de Valencia, 11. Valencia, Universidad de Valencia, págs. 150-184.

- (1980): «Reflexión en torno al arte levantino», Zéphyrus, XXVI-XXVII. Salamanca, Universidad de Salamanca, págs. 187-216

Lillo Cafpio, P. A. y Lillo Carpio. M. (1979): “Las pinturas rupestres de La Risca. Rincón de Pedro Gurullo, en Campo de San Juan (Moratalla)", Murcia, 3. Murcia, Diputación Provincial de Murcia.

LulL, V. (1983): La Cultura de El Argar. (Un modelo para el estudio socio-económico de las sociedades prehistóricas). Madrid, Ed. Akal, 487 páginas, 30 figuras, 11 tablas, y 94 gráficos.

Maluquer de Motes, J. (1970): "Orfebrería pre-romana en la Península lbérica", Pyrenae, 6. Barcelona, Universidad de Barcelona, págs. 79-100.

Marti OtIver, B. et alii (1980): "Cova de l'Or (Beniarrés, Alicante)", Trabajos varios del S.I.P., 65. Valencia, Diputación de Valencia.

Martinez Santaolalla. J. el alii (1947): “Excavaciones en la ciudad del Bronce Mediterráneo $\|$ de la Bastida de Totana (Murcia)", Informes y Memorias, 16. Madrid, Ministerio de Cultura.

Mateo Saura, M.A. (1992): Arte Rupestre Naturalista en Murcia. Aspectos socioeconómicos y etnográficos, Memoria de Licenciatura. Universidad de Murcia, 215 páginas, 36 figuras, 6 tablas, 6 mapas y 14 láminas (Inédita)

MELLAART, J. (1971): Çatal-Huyuck, une des premières citées du monde. Suisse.

Molina Gande, M. ${ }^{a}$ y Molina Garcia, J. (1973): Carta Arqueológica de Jumilla. Murcia, Diputación Provincial de Murcia, 207 páginas, 42 figuras y 42 láminas.

Molinos Sauras. M. ${ }^{a}$ I. (1986-7): "Representaciones de carácter bélico en el arte rupestre levantino», Bajo Aragón Prehistoria, VII-VIII. Zaragoza, Diputación Provincial de ZaragozaC.S.I.C., págs. 295-310.

Munoz AmibiLıA. A. M. ${ }^{\star}$ (1982): "La Edad del Bronce en el Sureste de España», XVI Congreso Nacional de Arqueología. Zaragoza. Universidad de Zaragoza.

Navarro Mederos. J.F. (1983); “La explotación del territorio en la Península Ibérica durante el Bronce Pleno», Tabona, IV. La Laguna, Universidad de La Laguna, págs. 29-93

Ortego Frias, T. (1948): "Nuevas estaciones de arte rupestre aragonés": el Mortero y Cerro Felío en el término de Alacón (Teruel)", Archivo Español de Arqueologia, XXI. Madrid Institución Diego Velázquez-C.S.I.C., págs. 3-37.

Porcar Ripolles, J.B. et alii (1935): “Excavaciones en Cueva Remigia (Castellón)”, Memorias de la Junta Superior del Tesoro Artístico, Sección de Excavaciones Memoria $136, n{ }^{\circ} 4$ Madrid, Ministerio de Cultura

Ripoll Perelló, E. (1963): «Pinturas rupestres de la Gasulla», Monografías de Arte Rupestre Levantino, 2. Zaragoza.

- (1968): "Cuestiones en torno a la cronología del arte rupestre post-paleolítico», Simposium Internacional de Arte Rupestre. Barcelona, Diputación Provincial de Barcelona, págs. 165. 192.

Rozor, J.G. (1978): Les derniers chasseurs. L'Epipaleolithique en France et en Belgique. Essai de synthèse. Charleville.

SAN NICOLÁS DEL TORO, M. et alii (1988): "Avance al estudio del conjunto con pinturas rupestres del Milano, Mula-Murcia", Bajo Aragón Prehistoria, VII-Vill. Zaragoza, Diputación Provincial de Zaragoza-C.S.I.C., págs. 341-346.

SiREt, L. y Siret, E. (1890): Las primeras edades del metal en el Sudeste de España. Barcelona. 
VARela, M. y Pinho, J. (1977): "Las estelas decoradas do Pomar (Beja, Portugal). Estudio comparado", Trabajos de Prehistoria, 34. Madrid, Centro de Estudios Históricos-C.S.I.F., págs. 165-214.

VINAS VALVERdu, R. et alii (1982): La Valltorta. Castellón, Ed. Castell, 189 páginas, 264 figuras.

WERNERT. P. (1917): “Nuevos datos etnográficos para la cronología del arte rupestre de estilo naturalista del Oriente de España", Boletin de la Real Academia Española de Historia Natural, XVIII. Madrid. 